\section{Habitat Characteristics and Preference of Himalayan Ibex (Capra ibex sibrica) in Hushe Valley in Central Karakorum National Park, Pakistan}

\author{
Ghulam Raza ${ }^{1 *}$, Maqsood Anawar ${ }^{2}$, Muhammad Akbar', Muhammad Ali ${ }^{1}$, \\ Alamdar Hussain ${ }^{1}$, Azhar Hussain ${ }^{3}$ and Tanveer Hussain ${ }^{4}$ \\ ${ }^{1}$ Department of Biological Sciences, University of Baltistan, Skardu, Pakistan \\ ${ }^{2}$ Department of Wildlife, PMAS-Arid Agriculture University Rawalpindi, Pakistan \\ ${ }^{3}$ Department of Food Science and Technology Karakorum International University \\ Gilgit-Baltistan, Pakistan \\ ${ }^{4}$ Department of Molecular Biology, Virtual University of Pakistan, Lahore, Pakistan
}

\begin{abstract}
A B S T R A C T
Himalayan ibex (Capra ibex sibirica) is a subspecies of Capra ibex, and is evenly distributed throughout the upper comparatively dry mountains of Gilgit-Baltistan, Pakistan. It is categorized as a Least Concern species globally as well as in Pakistan, however its presence in the Karakorum mountain plays a significant role in the economy of the region as dozens of trophy hunting of this specie takes place in the region every year and generates handsome money to the local inhabitants of the mountainous community. The characteristic habitat analysis and preference was important as the ibex move downwards during winter to cope the fodder shortage after heavy snowfall. This may expose the ibex to potential threats of predation by predators, poaching and competition for food with livestock during winter season. Therefore, the study was conducted to analyze the characteristic habitat feature and preference of Himalayan ibex during winter season in Hushe valley of Karakorum range.
\end{abstract}

\begin{tabular}{|c|}
\hline Article Information \\
\hline Received 13 June 2020 \\
\hline Revised 30 July 2020 \\
\hline Accepted 02 October 2020 \\
\hline Available online 23 July 2021 \\
\hline Authors' Contribution \\
\hline $\begin{array}{l}\text { The data is part of PhD Thesis of } \\
\text { GR. M Anawar was an advisory } \\
\text { member. M Akabr helped in writing } \\
\text { of the manuscript. M Ali helped in } \\
\text { data search. Alamdar } \mathrm{H} \text { helped in } \\
\text { data compilation. Azhar H and TH } \\
\text { contributed in proof reading. }\end{array}$ \\
\hline Key words \\
\hline $\begin{array}{l}\text { Coilia nasus, SSR markers, } \\
\text { Transcriptome. }\end{array}$ \\
\hline
\end{tabular}

\section{INTRODUCTION}

$I^{n}$ n Pakistan Himalayan ibex Capra ibex sibirica is the most abundant species of Caprinae in Pakistan (Schaller, 1977). It is limited to relatively dry peaks of the inner Himalayas, Karakoram, and Hindu Kush. Ibexes are equally widespread throughout higher mountain ranges of the Gilgit, Diamir, and Baltistan districts, and the northern part of the Chitral District.

The ibex predominantly inhabits mountainous regions from 5000-6,700 masl in rocky terrain and open alpine meadows and cliffs, comes down to lower elevations during the winter (Fedosenko and Blank, 2001). On a hot day prefers shaded areas, and the ibex tends to remain near steep, escape terrain (Fedosenko and Blank, 2001). Usually ibex live in herds of over 100 animals, but more typically forming small groups that vary considerably in size, averaging 6-30 animals, depending on the region (Reading et al., 1997, 1999, 2007, 2008; Fedosenko and Blank, 2001).

\footnotetext{
Corresponding author: ghulam.raza@uobs.edu.pk, ghrazabalti@yahoo.com 0030-9923/2021/0005-1823 \$ 9.00/0

Copyright 2021 Zoological Society of Pakistan
}

At day time, they spend the day in alternating periods of activity and rest. Himalayan ibex do not go too far away from cliffs, which serve as protection (Fedosenko and Blank, 2001). The cliff provides shelter during warm periods in the summer and during bad weather in the winter (Fedosenko and Savinov, 1983). Himalaya ibex live in a complex landscape, which apart from rugged mountains; comprises of alpine meadows for grazing, streams for watering, and level areas with scree between rocks for resting. They could stay on slightly sloping grassy areas for long periods or even incline to wet meadows for grazing and prefer steppe vegetation, firm soil, and areas with less snow cover during winter (Zavatskiy, 1990).

The distribution and number of Himalayan ibex depends on the availability of sizeable rocky areas and lack of deep snow. They avoid thick coniferous taiga tall grass, gentle slope and damp swampy areas (Sokolov, 1959). In the distribution of Himalayan ibex, depth of snow cover is an important factor and sometimes it is the only reason of their absence in some surrounding areas and mountains. Population density rises from the border towards the inner parts of mountains because of a decrease in snow level inside the interior parts. The species shows loyalty to their home range; animals troubled by predators coming back 
to their home place within some days. But, snow cover and lack of food in snowy areas forces them to seasonally change their home ranges or even migrate (Fedosenko and Savino, 1983). They move from the upper rocky zone to lower elevation during autumn, (Sobanskiy, 1988). In winter season they migrate from one mountain range to other sometimes and in so doing have been seen crossing valleys below $2135 \mathrm{~m}$ altitude (Roberts, 1977).

Anthropogenic activities in combination with livestock grazing have changed the numbers, distribution, and movements of ibexes. They were enforced to the steppes, flood lands and forest-steppes, to less favorable parts of the mountains (rocks, rocky deserts, and mountain tundra). The natural habitat was broken for numerous populations (Fil, 1977; Smirnov and Tkachenko, 1992).

In Hushe Valley, due to strict conservation efforts of local communities during the last one and half decades, the population of ibex is also expected to increase in combination with the livestock population, due to which there might be high pressure on rangeland of the valley especially during winter when ibex comes down in search of food. This study therefore intends to analyze the habitat characteristics and their preference in the Karakorum range of the valley.

\section{MATERIALS AND METHODS}

The study was conducted in the winter season from 15 November 2012 to 15 February 2013 (Fig. 1). The duration of the study period was constrained by the remoteness and inaccessibility of the study area. Two permanent transects, one $7 \mathrm{~km}$ in length upstream from Hushe village (centre point) to Dumsum Junction and the second $5 \mathrm{~km}$ long downstream from Hushe village (centre point) to Hushe bridge, were established along the Hushe river. Twelve major locations and three vantage points on each location were identified based on abundance of ibex population. Each trail was walked nine to ten times during the whole study period. Each time, observations while walking were made at all three vantage points of twelve locations. The total of 28 observations on average were taken. The Field observations were aided by $8 \times 40 \mathrm{~mm}$ binoculars and a 15 $45 \mathrm{X}$ spotting scope (1.2). When a group of animals was encountered, the location, time, date, species, number and habitat characteristics such as distance to the cliff, slope angle, elevation, and snow cover $\%$ were recorded in the designed format. The association of ibex with respect to habitat characteristics was calculated by taking the number of observations out of total 28 observations. All habitat variables were visually estimated except location and elevation, which was determined by using a Global Positioning System (GPS), model E Trex 30. For estimating the proportions of available habitat, Google Earth Pro was used to find out the total estimated covered area of the ibex habitat, with the help of GIS experts at the WWF office in Gilgit. The whole valley was sampled for the study of biomass cover and productivity in another study by the author; therefore, the habitat characteristics were easily noted during the survey in winter (Raza et al., 2014). The total area was estimated as $172 \mathrm{~km}^{2}$ with Google Earth Pro.

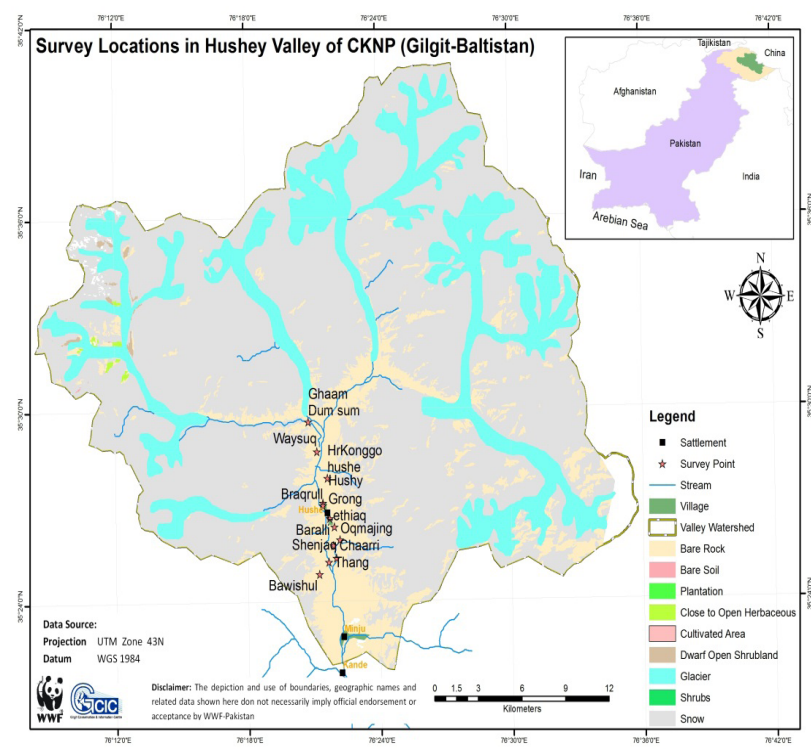

Fig. 1. Survey locations of Himalayan ibex in Hushe Valley during 2013.

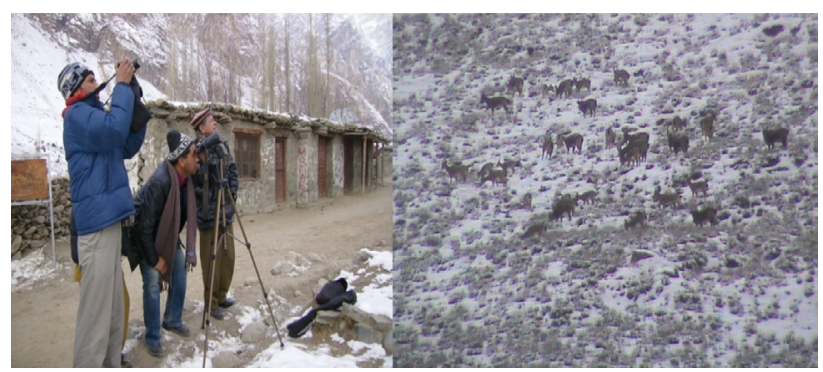

Fig. 2. Observing habitat of ibex in winter Hushe Valley 2013.

\section{RESULTS}

In $25 \%$ observations, ibex was found on slopes with partial snow cover, followed by $21 \%$ on cliffs and in $14 \%$ observations the ibex were found on areas fully covered with snow. Only $2 \%$ of the observations were on scree and barren areas. There was a significant difference in use of different habitat types(Table I). Ibex showed a preference for 
Table I. Distribution of ibex with respect to habitat types during winter 2012-13.

\begin{tabular}{|c|c|c|c|c|c|}
\hline Habitat type & Number of observations & Percent observation & $\chi^{2}$ & df & P value \\
\hline Cliff/Rocks & 6 & 21.43 & 5.5 & 1 & 0.019 \\
\hline Slopes with partial snow & 7 & 25.00 & & & \\
\hline Full Snow covered & 4 & 14.29 & & & \\
\hline Dry grassland patches & 3 & 10.71 & & & \\
\hline Broken areas & 4 & 14.29 & & & \\
\hline Scree (rock debris) & 2 & 7.14 & & & \\
\hline Barren & 2 & 7.14 & & & \\
\hline Total & 28 & 100.00 & & & \\
\hline
\end{tabular}

Table II. Distribution of Himalayan ibex with respect to cliff distance (m) in winter 2012-13.

\begin{tabular}{|c|c|c|c|c|c|}
\hline Distance to cliff & Number of observations & Percent observation & $\chi^{2}$ & df & $P$ value \\
\hline Very close to cliff $(1-25)$ & 8 & 28.57 & 3.714286 & 2 & 0.156118045 \\
\hline Close to cliff (25-50) & 14 & 50.00 & & & \\
\hline Away from cliff (51-80) & 6 & 21.43 & & & \\
\hline Total & 28 & 100.00 & & & \\
\hline
\end{tabular}

Table III. Distribution of Himalayan ibex with respect to slopes in winter 2012-13.

\begin{tabular}{llllll}
\hline Slope Angles (\%) & Number of observations & Percent observation & $\boldsymbol{\chi}^{2}$ & df & P value \\
\hline Very steep (90) & 4 & 14.29 & 6.5 & 2 & 0.038774208 \\
Steep (70-80) & 15 & 53.57 & & & \\
Moderate (60-70) & 9 & 32.14 & & \\
Total & 28 & 100 & & \\
\hline
\end{tabular}

Table IV. Distribution of Himalayan ibex with respect to altitudes in winter 2012-13.

\begin{tabular}{|c|c|c|c|c|c|}
\hline Altitude (m) & Number of observations & Percent observation & $\chi^{2}$ & df & P Value \\
\hline $3000-3200$ & 9 & 32.14 & 7.714286 & 3 & 0.05230078 \\
\hline $3200-3400$ & 12 & 42.86 & & & \\
\hline $3400-3600$ & 4 & 14.29 & & & \\
\hline 3600-above & 3 & 10.71 & & & \\
\hline Total & 28 & 100 & & & \\
\hline
\end{tabular}

sloping areas with a snow cover habitat. Almost 50\% of the observations of ibex were close to the cliffs, while only $21 \%$ of the observations were away from cliffs (Table II). There was a significant preference of ibex to live close to cliffs $(25-50 \mathrm{~m})$. Table III shows that $53 \%$ of Himalayan ibex were observed on steep slopes $(70-80 \%)$, 32\% were observed on moderate $(60-70 \%)$ slopes and there was a significant difference in the use of different slope angles. In the present study, $42 \%$ of the ibex were observed in between 3200-3400 m altitude and there was no significant difference in use of altitudinal variations (Table IV).

\section{DISCUSSION}

There was a significant difference in use of habitat types by the ibex. The high preference was shown towards slopes with partial snow cover habitats. Himalayan ibex preferred steep rocky areas in southwestern Laddakh, India (Fox et al., 1992). Schaller (1977) linked the affinity of Himalayan ibex for steep rugged terrain with avoidance of 
predation. Hussain (2010) showed that $15 \%$ of Himalayan ibex remain on smooth slopes in the Nagar district of Gilgit-Baltistan. Bhaatnagr (1997) found that Himalayan ibex spent $72 \%$ of their time on smooth areas as opposed to rocky areas in Laddakh, India.

The distribution with respect to cliff distance showed a significant preference of ibex towards areas close to cliffs (25-50 m), as 50\% percent of the observed ibex were in such habitats. This preference might be because the ibex want to avoid being preyed on by snow leopards. The findings of Feng et al. (2007) in China also support the present study. The $53 \%$ of Himalayan ibex were observed on steep slopes (70-80\%). There was a significant difference in use of different slope angles. Bhaatnagr (1997) also reported similar results for Himalayan ibex in Laddakh, India.

In the present study, $42 \%$ of the ibex were observed in between $3200-3400 \mathrm{~m}$ altitude and there was no significant difference in habitat preference at various altitudes. This may be because the ibex comes to a lower altitude in search of food. Snow cover and lack of food in snowy areas forces them to seasonally change their home ranges or even migrate (Fedosenko and Savino, 1983). They move from the upper rocky zone to lower elevations during autumn, (Sobanskiy, 1988). In winter season they migrate from one mountain range to other, sometimes have been seen crossing valleys below $2135 \mathrm{~m}$ altitude (Roberts, 1977).

This study revealed that there is a good population and considerable number of trophy sized ibex in the particular region during winter season, therefore, the number of licenses may need to increase for the sustainable conservation of ibex and co-existence of both livestock and ibex, to reduce the pressure on rangeland grasses.

\section{CONCLUSION}

There was a significant difference in the use of habitat types by the ibex. The high preference was shown towards slopes with partial snow cover habitats which showed link and the affinity of Himalayan ibex for steep rugged terrain to avoid predation. The distribution with respect to cliffs and steep slopes might be to avoid being preyed on by snow leopard. In the present study, the ibex came to lower altitudes in search of food. Snow cover and lack of forage in snowy areas forces them to seasonally change their home ranges. Therefore, there might be an increased risk of predation by snow leopard and poaching by hunters. The downward movement in winter may also cause shortage of food for domestic livestock and competition may occur among them. The results of the study will be helpful for conservationists for planning of conservation strategies.
Statement of conflict of interest

The authors have declared no conflict of interest.

\section{REFERENCES}

Bhatnagar, Y.V., 1997. Ranging and habitat utilization by the Himalayan ibex (Capra ibex sibirica) in Pin Valley National Park. Ph.D. thesis, Saurashtra University India. pp. 403.

Fedosenko, A.K. and Blank, D.A., 2001. Capra sibirica, mammalian species. Am. Soc. Mammalogists, 675: 1-13. https://doi.org/10.1644/15451410(2001)675<0001:CS $>2.0 . \mathrm{CO} ; 2$

Fedosenko, A.K. and Savinov, E.F., 1983. The Siberian ibex. In: Mammals of Kazakhstan (eds. E.V. Gvozdev and V.I. Kapitonov). Nauka Kazakh SSR, Alma-Ata. pp. 1-246.

Feng, X., Ming, M. and Yiqug, W., 2007. Population density and habitat utilization of Capra ibex in tomur national nature reserve of Xinjiang. China. Zool. Res., 28: 53-55.

Fil, V.I., 1977. The Siberian Ibex of the central part of the east Sayan. Nauka, Moscow, USSR. pp. 239240.

Fox, J.L., 1996. Rangeland management and wildlife conservation in Hindu Kush-Himalayas (HKH). In: Proceedings of rangelands and pastoral development in the Hindu Kush-Himalayas. Proc. Reg. Expt. Meet., pp. 53-57.

Fox, J.L. and Johnsingh, A.J.T., 1997. Wild sheep and goats and their relatives: status, survey and conservation action plan for Caprinae. International Union for the Conservation of Nature, Gland, Switzerland. pp. 215-231.

Fox, J.L., Nurbu, C. and Chundawat, R.S., 1991. The mountain ungulates of Ladakh, India. Biol. Conserv, 58: 167 190. https://doi.org/10.1016/00063207(91)90118-S

Fox, J.L., Sinha, S.P. and Chundawat, R.S., 1992. Activity patterns and habitat use of ibex in the Himalayan Mountains of India. J. Mammal., 73: 527-534. https://doi.org/10.2307/1382018

Hussain, M., 2010. A study on Himalayan Ibex in Nagar valley Gilgit Baltistan. M.Phil thesis, Department of Wildlife Management, PMAS-Arid Agriculture University Rawalpindi, Pakistan. pp. 105.

Namgail, T., Fox, J.L. and Bhatnagar, Y.V., 2004. Habitat segregation between sympatric Tibetan argali Ovis ammon hodgsoni and blue sheep Pseudois nayaur in the Indian Trans-Himalaya. J. Zool., 262: 57-63. https://doi.org/10.1017/S0952836903004394

Namgail, T., Bhatnagar, Y.V. and Fox, J.L., 2006. 
Pastoral production and wildlife conservation in a trans-Himalayan wildlife reserve in Ladakh. Issues of Pastoralism in the Himalayan Region. G. B. Pant Institute of Himalayan Environment and Development.

Raza, G., Mirza, S.N., Akbar, M., Hussain, I., Ali, M., Hyder, S., and Ahmad, N., 2014. An assessment of surface features and vegetative cover in Alpine Rangelands of Central Korakoram National Park region, Pakistan. J. Biodiv. environ. Sci., 5: 274279.

Reading, R.P. and Shank, C., 2008. Capra sibirica. In: IUCN 2014. IUCN red list of threatened species.

Reading, R.P., Amgalanbaatar, S. and Lhagvasuren, L., 1999. Biological assessment of three beauties of the Gobi national conservation park, Mongolia. Biol. Conserv., 8: 1115-1377. https://doi. org/10.1023/A:1008900427566

Reading, R.P., Amgalanbaatar, S., Kenny, D., DeNicola, A. and Tuguldur, E., 2007. Siberian ibex (Capra ibex sibirica) home ranges and Ikh Nart nature reserve, Mongolia: Preliminary findings. Mongolian J. biol. Sci., 5: 29-37. https://doi.org/10.22353/ mjbs.2007.05.05

Reading, R.P., Amgalanbaatar, S. and Mix, H., 1997. Argali ovis ammon surveys in Mongolia's South Gobi. Oryx, 31: 285-294. https://doi. org/10.1046/j.1365-3008.1997.d01-17.x

Roberts, T.J., 1977. The mammals of Pakistan. Ernest
Benn Limited, London, United Kingdom.

Roberts, T.J., 1997. Mammals of Pakistan. Revised edition. Oxford University Press, Karachi, Pakistan, pp. 525.

Roberts, T.J., 2005. Field guide to the large mammals of Pakistan. Oxford University Press, Oxfrod, UK. pp. 282.

Schaller, G.B. and Gu, B.Y., 1994. Comparative ecology of ungulates in the Aru Basin of northwest Tibet. Nat. Geog. Res. Explor., 10: 266-293.

Schaller, G.B., 1977. Mountain monarchs: wild sheep and goats of the Himalayas. University of Chicago Press, Chicago. pp. 525.

Schaller, G.B., 1998. Wildlife of the Tibetan steppe. University of Chicago Press, Chicago. pp. 425.

Smirnov, M.N. and Tkachenko, V.A., 1992. The Siberian ibex in the south Siberia. In: The ecology of the game animals of the Siberia (ed. M.N. Smirnov). Krasnoiarsk University, Russia, pp. 71-95.

Sobanskiy, G.G., 1988. The game animals of the Altai Mountains. Nauka, Novosibirsk, USSR.

Sokolov, I.I., 1959. Siberian ibex. In: Fauna of the USSR: Mammals (ed. E.N. Pavlovskiy). Academy of Sciences of the USSR, Moscow, Leningrad. pp. 416-442.

Zavatskiy, B.P., 1990. Ecology of the Siberian ibex of the west Sayan. Shushenskoe, USSR (in Russian). pp. 32-34. 